Article

\title{
The Application of Yantian Cultural Resources in Design Education-Taking the Yantian Community in Tainan as an Example
}

\author{
Wei-Han Chen ${ }^{1, *}$ and Ta-Hsiang Ho ${ }^{2}$ (D) \\ 1 Graduate School of Applied Design, Tainan University of Technology, 529, Zhongzheng Rd., \\ Yongkang District, Tainan City 71002, Taiwan \\ 2 Graduate School of Design, Master Program, National Yunlin University of Science and Technology, \\ 123 University Road, Section 3, Douliou, Yunlin 64002, Taiwan; john830601@gmail.com \\ * Correspondence: tb0085@mail.tut.edu.tw; Tel.: +886-391-87786
}

Received: 31 January 2020; Accepted: 10 March 2020; Published: 27 March 2020

check for updates

\begin{abstract}
Salt" is an indispensable necessity in people's livelihood. In Taiwan's islands surrounded by the sea and the western coastal areas, salt was boil the sea for a long time in the early stages, and seawater was introduced into the depression in the later stages and evaporated in the sun. With the development of the times, different characteristics of the construction and building materials in the field of the salt industry have entered the era of the industrial revolution. With the development of technology, salt processing technology and the use of imported salt in foreign trade have forced salt fields to be abandoned along with historical development. The Yantian cultural relics still preserved today are actively preserved by government departments to continue to apply the Yantian culture. This study selected the Yantian community in Annan District of Tainan City as the focus of planning. It is hoped that through the development of design education, it will emphasize practical ability and practice-oriented research. The study combines design practice and practical theory, based on the original ecological culture of Yantian, through the reconstruction plan of Yantian's cultural resources, the mobilization of residents in the Yantian community and the tourism planning of the Yantian Cultural Village, to find a transition direction suitable for the Yantian Cultural Village. Market needs with combining core values of the community with a patchwork of practical experience and action research to build participatory research theories will result in effective internal practice and learning. This research adopts the method of service research through service design, including: 1. diagnosing problems; 2 . choosing solutions; 3 . seeking cooperation; 4 . implementation; and 5. assessing the response from a practical perspective, with the importance of action research, where "Yantian" combines with the local "salt-making" characteristic culture, develops cultural innovation experience, and guides students to truly enter the community to learn. The plan explores the possibility of long-term introduction of design education in the local community, discusses how to communicate and collaborate with community residents, and uses design tools to help solve the problem of community image promotion and application. The research results finally put forward the preliminary construction of the role of the Tainan Yantian community volunteers as a design education platform based on practical experience. It is hoped that it can be used as a local practice of design education and as an accumulation of reference experience.
\end{abstract}

Keywords: Yantian culture; community development; design education

\section{Introduction}

The location of Yantian Ecological Culture Village is currently adjacent to the Northern Shanwei Waterfowl Conservation Area in the Taicao Wildlife Sanctuary of Taijiang National Park. Its salt 
field space integrity and precious ecological resources have given the value of salt field building activation and ecotourism development. We sought to understand the development content and development progress of the current Yantian Ecological Cultural Village, and find out the current problems and solutions. We used relevant literature content, regulations and content analysis of related plans, from the history of Yantian development to the establishment of Yantian Cultural Village today, to effectively plan this space and develop and propose eco-tourism strategies. Combined with surrounding tourism resources and salt culture, as a historical and cultural heritage site and restoration of ecological resources, and the development of educational and experience, we proposed a guide view trip for travel planning. The purpose of this study is to enhance the attraction of the salt industry culture here, to try to activate and reuse the Yantian cultural space, and to combine nature conservation as eco-tourism. The predecessor of Yantian Cultural Village is Anshun Yantian. Currently, it is a rare and well-preserved Yantian landform area in Taiwan, which can promote the rejuvenation of cultural landscape and ecological environment. Through this study, the culture and resources related to the Tainan Yantian community were compiled, and the salt industry's cultural resources of the Yantian community were transformed into a cultural and creative tourism industry. The main research objectives are as follows:

(1) Sort out the cultural resources of the Tainan Yantian community and the characteristics of the Yantian community.

(2) Understand the cultural characteristics of the Tainan Yantian community and how communities can turn cultural behavior into creative development requirements.

(3) To understand the Tainan Yantian community transformation with its cultural and creative combination of sightseeing, experiences and souvenirs.

\section{Literature Review}

\subsection{Community Experience Learning}

The concept of experiential learning is initiated by John Dewey's innovative education of learning by doing. It is believed that education should help students grow their minds in all directions. Experience is the main source of cognition, so it is also related to "experience learning" (or experiential learning). Experiential learning, is "similar to the concept of learning", so that learners are directly learning from experiences and are gaining increased significance and insights [1]. Most of the core concepts of experiential learning come from Kolb, which divides learning into four main stages, namely: 1. specific experience; 2 . observation and reflection; 3 . abstract concepts and classification; and 4 . initiative in new contexts. Verification of the concept of connotation, through each stage of experiential learning, allows learners to have different abilities to transform [2].

Burgoyne and Hodgson (1983) believe that individuals experience learning in their daily lives, not only from courses, but especially because of the importance of doing secondary school (i.e., learning from experience), creating a gradual or default change that can change a person's point of view or attitude. It is not only to reflect on the past experience, but also to learn the meaning brought about by experience, and to take action to test the feasibility of the solution, in order to have a higher level of participation in learning [3]. This research project seeks to implement the design of the Yantian community in Tainan. The Yantian, which has been open since the Japanese occupation period, has become an important place for historical culture and ecological conservation, from industrial production to tourism and conservation, combining historical humanities with ecological conservation, and resuscitation and activation as the main orientation.

\subsection{Distribution and Historical Context of Tainan Yantian}

"Salt" is an indispensable necessity in people's livelihood. According to the literature, as early as in the Dutch period, the salt industry process was used in the coastal areas of mainland China in addition to boiled seawater for a long time. Salt products were transferred to Taiwan in the Wuhu area. 
In 1639, in Taiwan, Da Gou had already produced salt, and later, its salt production area evolved into the south of the field. During the Ming and Zheng Dynasties, in 1665, Zheng Chenggong's joined the army, Chen Yonghua, opened up Laikou Salt Mine in Tainan. At the same time, he began to formulate a salt tax system and planned salt production, and opened up the salt industry into the history of Taiwan for more than 300 years [4]. Exploring the history of the salt industry after 338 years finds the cooking of salt, salt itself, industrial production to the final waste, and replacing salt with imports. The salt industry represents the industrialization of people's lives and is an indispensable product in life. The relationship between Yantian and the cost of salt was reduced in the Republic of China 70 years later. Salt was completely sun-dried in the Republic of China in 1991. The industrial sites and ecological environment left behind after the waste, as well as the historical records and cultural values, are preserved and passed down through relevant literature review and human records. Construction and salt migration through the analysis of research and analysis over the past 338 years (1665 years 2002 years) developed the era of solar salt, and the salt industry's history over the evolution of the times has been derived from different characteristics. In the 18th year of Yongli (1664), in the record of Zheng's "Taiwan Armament Map", the word "salt and salt" was written near the Lai Kou, indicating that the new salt-making technology appeared at that time. The Lai Kou due to an increase in salt and gradually formed a settlement. From the only remaining sketch of the Ming and Zheng Dynasties in Taiwan, we can understand the importance of "salt" to the military. The prosperity of Sakaguchi Village has made the Sakaguchi Village the birthplace of the salt field in Taiwan's history because of the levy of salt and salt tax. In 1665, Chen Yonghua taught the people to salt in the Lai Kou, and changed the salt-making technique that had tasted bitter to the salt that had dried in the sun. He introduced seawater from the inland sea of the northwest side and built the "salt salt field" (now Tainan salt). The southern part of the region was later renamed the Yubei field.

\subsection{Yantian Cultural Heritage-Salt Technology}

The predecessor of Yantian Ecological Culture Village is Anshun Salt Field. Since 1919, it has started to produce salt. It was the Taiwan Salt Association in the Japanese occupation period. The nearby five-point railway leads to Yongkang, and the Yunyan Canal leads to Pingyang. The rapid evolution and mechanization of the technology caused the salt industry to gradually transform, due to the relationship between quality, cost and operation, and later replaced the production with imported salt, so that the Anshun Salt Field was officially suspended in 1994. Then, in the history of the salt industry, cultural heritage and the importance of recycling industrial sites, prompted the establishment of the "Yantian Ecological Culture Village" by the Cultural and Cultural Construction Association, retaining the important facilities of the salt industry in the region and the historical site of the salt production process at that time [4]. This study investigates the past Yantian Ecological Culture Village, located in Anshun Salt Field in Annan District. It was the first salt-making industrial zone in Taiwan during the Japanese occupation era. It began construction in 1919. It took four years to complete, completed in 1923, and in western Taiwan. The "wapan salt field" used for salt was called "Tiantian Yantian" in the early days. The Yantian community incorporates old tribes such as Nanxun, Beibei and Sandong, and the newly moved 125 Tailong community from Tainan City, 400 new communities of mangrove communities and Tainan City, in addition to the workers and employees of the science and technology area, as well as a small number of foreign workers. Therefore, the Yantian community can be said to have formed its unique community culture from an old tribes' residents and a new village with the residents of the science and technology area and the foreign workers. In Yantian's building materials, Taiwan's Yantian category is based on the difference in the material laid in the crystallization pond, which is divided into "earth" and "tile". In the early days, most of the wafers were in Yantian, and the cylinders used in the bottom of the crystallization pool were extracted from Fujian. During the Japanese occupation period, a large amount of industrial salt was needed. Therefore, the area of Yantian was rapidly expanded, but the price of the cylinder was expensive. It was not easy. The 
Yantian field set up in the later period has been changed to a soil plate [4]. The comparison of salt field types is shown in Table 1 (Taiwan National Park Campus Overall Facilities Planning Guidelines, 2012).

Table 1. Comparison table of salt field types.

\begin{tabular}{|c|c|c|}
\hline Kind & Earth Plate & Tile \\
\hline Crystallization pot laying material & Sand is combined with clay. & Tile inlay. \\
\hline Salt collection time & $\begin{array}{l}\text { The salt formation is slower and the } \\
\text { harvest period can be harvested in about } \\
\text { three days. }\end{array}$ & $\begin{array}{l}\text { The bottom tile of the pool is more } \\
\text { heat-absorbing than the soil, so the salt is } \\
\text { formed faster. It can be harvested in one } \\
\text { day in the big flood season, and it can also } \\
\text { be used in a short period of time. }\end{array}$ \\
\hline $\begin{array}{l}\text { Storage tank } \\
\text { Yield }\end{array}$ & $\begin{array}{l}\text { No settings. } \\
\text { Each area is about } 4.85 \text { hectares, with a } \\
\text { large area and a large total output, but the } \\
\text { output per unit area is less than the tile. }\end{array}$ & $\begin{array}{l}\text { There are settings. } \\
\text { Each sub-area is about } 0.9 \text { hectares, the area } \\
\text { is small, the total output is less than the soil } \\
\text { plate, but the output per unit area is higher. }\end{array}$ \\
\hline Yancheng maintenance & $\begin{array}{l}\text { After three to four harvests, the bottom of } \\
\text { the crystallization pond must be } \\
\text { thoroughly cleaned and ground. }\end{array}$ & \\
\hline Salt characteristics & $\begin{array}{l}\text { The bottom of the process is made of soil } \\
\text { and paved. The leakage is large, so the } \\
\text { crystal particles are larger. As it contains a } \\
\text { little mud, the color is dim, but because of } \\
\text { the slower salt formation, the crystals are } \\
\text { firm and salty. }\end{array}$ & $\begin{array}{l}\text { The bottom of the process is paved with } \\
\text { tiles and has less leakage of halogen. } \\
\text { Therefore, the crystal particles are small } \\
\text { and white, but because of the rapid salt } \\
\text { formation, the impurities are still present } \\
\text { in the salt, and the crystals are also weak. }\end{array}$ \\
\hline The main purpose & Industrial use & Edible \\
\hline
\end{tabular}

(Source: Strategic Planning of Cultural Landscape-Oriented Parks, 2011).

The project was visited on the spot to gain an in-depth understanding of the elders or the next generation who are operating Yantian in the Yantian community in Tainan. They will understand the history and characteristics of the past, collect and consolidate, and classify the differences for comparison. They presented the local culture through video and audio, interviewing the story with the elders, introducing local characteristics into planning and analysis, and collecting them to inform the tourists and to let the public know more about the cultural characteristics of Taiwan's Yantian. They were able to cultivate specialized commentators, introduce regional development characteristics and historical and cultural backgrounds, and introduce talents in Yantian culture. With salt drying technology, they were able to create employment opportunities in Yantian area of Tainan, and enhance the skills of youth returning to the countryside, which aids in regional development, and promotion of a century-old historical background.

The application of Yantian cultural resources and the development and discussion of Yantianli area, Figure 1 understands the transformation from industrial production to tourism and conservation, combining historical humanities and ecological conservation, and the restoration and activation as the main guidance as the main goal of salt field space planning Through the analysis of relevant literature and experts, this study uses eco-tourism scholars' interviews to find appropriate development methods and directions. The research scope is currently designated as Taijiang National Park, which is adjacent to Beishanwei Waterfowl Reserve. Therefore, in terms of spatial planning and reuse, the principle of low-level development is the main principle. Explore the role and limitations of the area in the area, use relevant plans and case studies as the basis for reuse, and finally explore the current development issues through practical action research, and understand the operation of service design to understand Tainan Yantian The community transformation of culture and innovation combines the steps and orientation of tourism to make its field space sustainable development and preservation. 


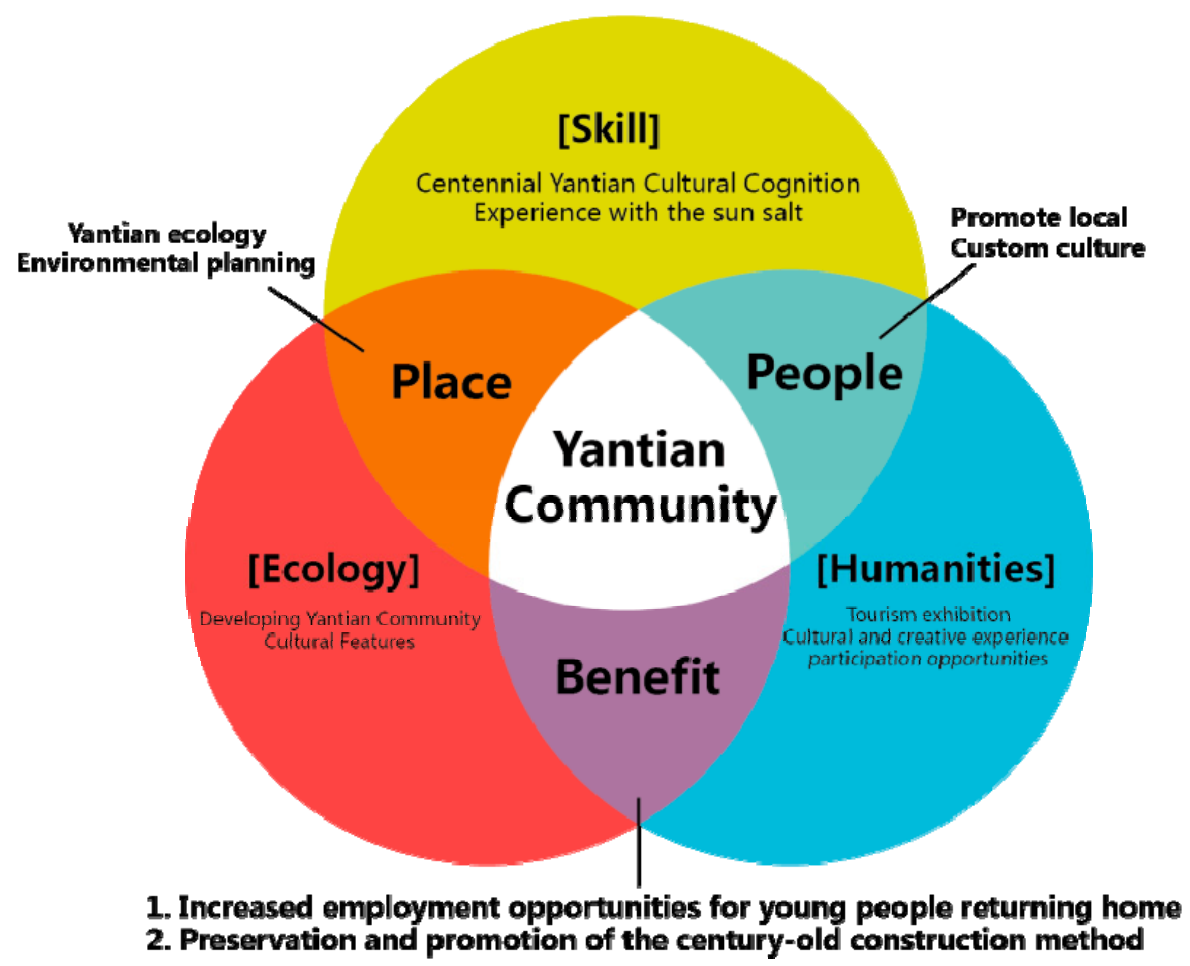

Figure 1. Research architecture and description (Source: Drawing in this study).

\section{Materials and Methods}

\subsection{Research Architecture}

After the analysis of this study, it is believed that the Tainan Yantian community now needs to rebuild the Tainan Yantian project to create a special sightseeing tour that can be implemented for a long time, open up the local salt experience course, create employment opportunities in the local area, and enhance the willingness of the youth to return home. This is in order to let everyone re-recognize the definition of Wenchuang, combined with local humanities and techniques, develop the skills of salt drying in the earth and the construction of unique salt fields, open up the innovative experience of the text, and experience the life of Yantian traditional salt workers that cannot be experienced in other areas. In addition, the community can plan local scenic spots, create Yantian eco-tourism and sightseeing, make features with gifts, deepen the impressions of tourists, and then achieve marketing effects and promotion, attracting more tourists. The research process is divided into three parts, as shown in Figure 2. The first part is "Pre-preparation and data collection", the second part is "Workshop Period and Data Collection", and the third part is "Analysis of Community Experience Learning Co-creation Workshop". Relevant information, as well as the relevant research processes and methods are as follows.

Through the first part of the theoretical discussion of analytic literature, we drew up the initial study architecture and interview questions, as salt in the search field investigation direction based on set. We also confirmed the workshop topics promoted by this research, with liaisons and preparation of the workshop. The second part is the interactive mode of the research workshop, which allows students to grasp the characteristics of the salt-salt technology and the needs of the residents in the salt fields of Taijiang. Through communication and planning with the members of the workshop, the students try to jointly solve the problems faced by the residents in Yantian by interviewing the local residents about the workshop experience and newly discovered issues. The third part is the first-hand information such as interviews and workshops in this study. Then, the literature theory and related materials are integrated and analyzed. In the trend of Yantian cultural eco-tourism autonomy and community re-engineering, this research hopes to introduce the design practice to the Yantian 
community. Through the interaction of the cross-disciplinary team's design workshops, in addition to reaching the student community to experience learning, the Yantian community will also be reached. The practice and review of community building is expected to help the Yantian community to preserve the traditional culture of Yantian while improving the local salt industry's affirmation of traditional culture, economic income, and reaching out to visitors. There are still many problems to be solved in the community, such as outflows, ecological environment protection, cultural heritage, etc., which are urgent social problems that need to be solved. Therefore, the design workshop tried to solve the problem of the Yantian community by facing major issues through the design proposal of the workshop. It also intended to induce the local residents to think about the development and dilemma of Yantian culture and ecology, which is a process of designing and training.

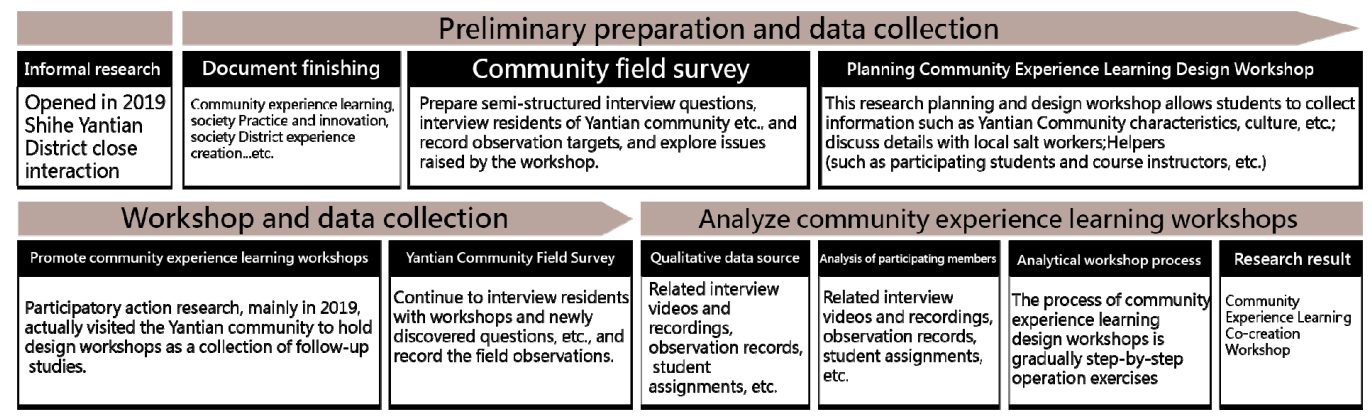

Figure 2. Process and method (Source: Drawing in this study).

\subsection{Research Methods and Analysis}

This research uses qualitative research methods. Mainly, qualitative information is suitable for turning theoretical knowledge into practical action, and human-centered related research can use "participatory observation, ethnography" and other methods, and can also use innovative "design workshops" to carry out the research. The significance of this innovation, is not in adding new technology and other new inventions, but breaking the old patterns of thinking and behavior, so that the researchers who fill out questionnaires from traditional face to face interviews or research, are converted to active research participants. Furthermore, students or seniors are invited to join in creating a community design workshop, and the process of this research gleaned from the workshop provided useful research information. Such a method outweighs traditional research methods, which can present periods of creative generation or are difficult to express [5].

This study uses design workshops to help Tainan Yanjiang Litian to enhance the overall strategy, and promote practical design workshops so that participating members can grasp the context and current situation through practical participation, and put ideas into practice in an experimental way to improve participation. This is the rationality and feasibility of action research. In this study, Participatory Action Research (PAR) was used as the research method. The action of the proposed design workshop was used as the analysis content. The participating members made possible methods to solve the problems according to the actual problems they encountered in actual implementation. Problems, evaluations in the process, feedback, revisions, and finally, implementation of these methods, aided in short-term exploration of community issues and implementation of solutions. The participatory action research department proposes analysis and countermeasures (abstract theoretical thinking) for the problem to be solved, then implements the real situation (figurative thinking), then reviews the analysis and implementation, and then re-generates the cycle of the new countermeasures. The experience and the unsuccessful actions continue to circulate this process. The biggest characteristic is to solve the problems in the real situation, verify these problems from the research process, solve the problems and improve the feasibility of the theory, as well as pay more attention to the team members. Participation and cooperation is a "solving problem-oriented" research method that emphasizes staged critical reflection, problem change, improvement process, etc., meaning that after 
"problem-reflection-summary-plan-action-discovery", the process of re-reflection occurs (McTaggart, 1991; Walter, 2009) [6]. The promotion workshop is mainly to stimulate the old people in the Yantian community in Tainan, to rethink the relationship between culture and industry, take the initiative to care for the people in the community, try to solve the problems that the community is currently experiencing, and finally, grow eager to achieve social practice and innovation.

Learn from Table 2 the analysis includes: 1 . In-depth interviews: During the study period of this project, formal interviews were conducted with the elderly and salt field operators in the community, including the village head, the chairman, the Yantian Community Development Association cadres and members, in order to better understand the problems encountered by the community and administrative planning such as cultural industry development, through interviews with administrative staff of Taijiang Township Office; 2. Documentary materials: Student homework and experience, workshop briefings, guidebooks, etc.; 3 . Participatory observation method: Reflecting community learning from promoting community experience learning. The possibility of practice: Take the design workshop in Yantian as an example to directly observe the workshop and record the observation notes; 4 . Physical objects: Supplies, products, service prototypes, exhibition posters, workshop video recordings and photos.

Table 2. Step flow.

\begin{tabular}{lllll}
\hline \multicolumn{1}{c}{ Gather Information } & \multicolumn{1}{c}{$\begin{array}{c}\text { Field } \\
\text { Investigation }\end{array}$} & Design Symbol & $\begin{array}{c}\text { Experience } \\
\text { Operation }\end{array}$ & Promote Local \\
\hline $\begin{array}{l}\text { Regional distribution } \\
\text { Field visit }\end{array}$ & $\begin{array}{l}\text { Yantian } \\
\text { resident interview } \\
\begin{array}{l}\text { Traditional salt drying } \\
\text { technology }\end{array}\end{array}$ & $\begin{array}{l}\text { Local } \\
\text { characteristics } \\
\text { in the salt industry } \\
\text { Local attractions }\end{array}$ & $\begin{array}{l}\text { Traditional skills } \\
\text { Salt culture } \\
\text { Yantian experience }\end{array}$ & $\begin{array}{l}\text { Featured products } \\
\text { Creative goods } \\
\text { Making audio and video }\end{array}$ \\
\hline
\end{tabular}

(Source: This study).

\subsection{Research Methods}

This research method is based on the action research method, and the action refers to the action of the "reflective practitioners" (Schon, 1983), including, at least: 1. Diagnosing the problem; 2. Selecting the plan; 3. Seeking cooperation; 4. Implementing the implementation; 5. Comment and detect the reaction. The significance of action research, from a practical point of view, is a practical worker's actual action situation, taking concrete actions and research, and improving practical work; from a reflective point of view, it is to encourage practical workers to reflect on practical work. From a professional point of view, through the action and the actual work research, to enhance the quality of professional activities; from the perspective of professional groups, action research is to support the practical workers and their professional groups, and can effectively respond to practical work challenges. In the way of reflecting on thinking and creating reforms, we should respond to the actual work situation [7]. The characteristics of action research include: 1 . It is an intentional action; 2 . It is an action based on informational materials; and 3. It is a professionally committed action. Action research includes, at least, diagnosing the problem, options, seeking cooperation, implementation and evaluation of the implementation of anti-practice with five different actions should wait. These divisions of action can assist practitioners in identifying different levels of reflection thinking in the practical actions of action research [8]. One theoretical basis for action research, is practitioners' rational reflection, "according to practice moral critique of liberation (Reflective rationality) instead of instrumental rationality (Technical rationality) [9], and areas for substantive work (Reflection and reflection) [10].

In the field of practical reflection, the reflection of action research includes the following five different modes of reflection thinking. The first type of analysis and diagnosis is the reflection of "diagnosis"; the second kind of deliberation is that there is an introspection about the "development plan"; the third type of synergy is the reflection of the collaborative partners who seek "cooperation"; the fourth kind of monitoring response is the reflection on "Implementation of the project". The 
fifth evaluation feedback is a reflection on the "evaluation response". In particular, the focus of the assessment is to pay close attention to the value of the expected and unanticipated results after implementation [11].

\subsection{Research Design}

Yantian is one of Taiwan's unique salt-making cultures. In the process of artificial salt production, there are many important processes, observations and judgment capabilities. However, those who have these skills and accumulated experience can continue to pass on their knowledge. It is a very important topic now. At present, Yantian Ecological Cultural Village teaches Yantian-related knowledge through an appointment-based, fee-based experienced guide, but no one uses design to present it. Learn from Tables 3 and 4 This study will use the skills learned to transform and visualize the design and use creativity to promote it; not only the visual performance, but also the Yantian culture and history, so that each design has a different appearance. However, this study is not only to promote the heritage and cultural assets, but also plans to extend the development of cultural and ecological tourism in Yantian, and Yantian activation in the Tainan community, to write down the next steps in Yantian culture for these older farmers who are the original salt farmers.

Table 3. Short-term, medium-term, and long-term planning.

\begin{tabular}{|c|c|}
\hline Short-term planning & $\begin{array}{l}\text { 1. Visit the salt farmers in the Yantian community in Tainan, collect } \\
\text { historical materials, and learn about local culture. } \\
\text { 2. Local characteristics analysis and planning. } \\
\text { 3. Produce audio and video in local culture. }\end{array}$ \\
\hline Medium-term planning & $\begin{array}{l}\text { 1. Create employment opportunities and increase youth returning for } \\
\text { opportunities. } \\
\text { 2. Cultivate talents, such as sales staff, tour guides. } \\
\text { 3. Promote the salt-making skills of Yantian with a long history. }\end{array}$ \\
\hline Long-term planning & $\begin{array}{l}\text { 1. Preserving traditional techniques such as Yantian culture and salt- } \\
\text { making experience. } \\
\text { 2. Develop local ecological tourism features and create art villages. } \\
\text { 3. Promote local specialty products such as souvenirs, etc. }\end{array}$ \\
\hline
\end{tabular}

(Source: This study).

Table 4. Design Activity Photo Introduction.

\begin{tabular}{l} 
Activity Photo 1 \\
\hline $\begin{array}{l}\text { Activity Photo } 2 \\
\text { Diagnosing problems. Visiting } \\
\text { local salt-dwelling seniors. } \\
\text { phrough action research, support } \\
\text { profession workers and their } \\
\text { respond to practical work } \\
\text { challenges, to reflect on thinking } 3 \\
\text { and training. }\end{array}$
\end{tabular} \begin{tabular}{l}
$\begin{array}{l}\text { The actual participation of the } \\
\text { people through the } \\
\text { implementation of the } \\
\text { participatory observation method, } \\
\text { from the traditional face-to-face } \\
\text { questionnaire survey or interview } \\
\text { research by the researcher, turned } \\
\text { into an active research participant. }\end{array}$ \\
$\begin{array}{l}\text { "implementation and } \\
\text { implementation". Actually } \\
\text { visiting Yantian, investigating and } \\
\text { video record. }\end{array}$ \\
\hline
\end{tabular}

(Source: This study). 


\section{Results}

This study is expected to be transformed into a conditional project for the development of service design through the local design workshop of the Yantian Community in Tainan. By combining the products on the ground, the product will be given as a local specialty product. It is hoped that young people in the local area will be able to return home and actually make joint efforts for the sustainable operation of the region. This plan provides services for the returning youth and provides the value of local promotion. Through the overall design of the community, the study hopes to plan local characteristic buildings, regional activities, and promote local tourism value, providing an increase in additional income. Combining the link between the local songs and the cultural heritage, it is expected to follow the characteristic journey and continue to operate with the local tourism industry to improve the long-term lack of tourism planning in the Yantian community in Tainan. In fact, the seven shares of Tainan are rich in natural resources and natural beauty. The Tainan Yantian community redevelopment project was carried out through design planning for local community transformation opportunities. When the tourists actually visit Tainan Yantian, they can directly experience the operation of Yantian and understand the local cultural background through the stories shared by the salt farmers, and they can also pass this on. The study also hopes to create employment opportunities for young people returning to their hometowns and promote the recognition of the land and the ecological education in Yantian.

\section{Design Planning and Expected Benefits}

Learn from Table 5 This study hopes that through the reconstruction of Yantian culture, the mobilization of community residents, and the return of Yantian cultural and ecological tourism, the core values of the community will be combined and preserved, and the Yantian cultural ecology will continue to spread with the following ideas:

1. Planning local characteristics, combining tourism industry.

2. Enhancing the employment opportunities of young people returning home, and cultivate talents.

3. Planning an art community to promote tourism activities in the Yantian area of Tainan.

4. Promoting the preservation of the art culture through traditional experiences.

5. Combining local characteristics and develop regional specialty product design.

- Short-term goals-planning local cultural promotion

Through the construction plan of Yantian Cultural and Ecological Tourism, the culture of the Yantian community and traditional salt production and the tourism characteristics of Tainan Yantian community will be promoted. The project, in conjunction with local units in the Yantian community in Tainan, worked together to revitalize the Yantian community in Tainan, providing local young people and stores to promote the development of the tourism industry in the region, and to develop different goals through the various stages of the project. With the content, it is expected to provide sustainable Yantian cultural ecology and local awareness, jointly promote local tourism opportunities, and produce audio and video in the local culture.

- Mid-term goal—cultural retention skills heritage

Let more people know about the Yantian ruins and traditional salt-making cultures with a long history. By understanding and experiencing, they will achieve the spirit of perpetual culture and be marketed through the implementation and planning of the project. Developed in the creation of geography and technical guidance, coaching manufacturers to innovate Wenchuang packaging design. Let the people experience the activities in person, learn the traditional salt-making techniques and feel the follow-up inheritance problems. Handle the local youth innovation exchange and talent training workshop to promote tourism industry matchmaking.

- Long-term goal—sustainable culture in local culture and tourism 
The overall construction of the community combines local architecture, hosts local cultural festivals, expands the value of local tourism, attracts more tourists, and builds a tourist attraction. It will enhance the value of salt farmers' self-identification, and improve the awareness and value of the traditional salt industry by the public and the salt farmers themselves, thus improving the current situation of human resource loss. Through the improvement of the sense of value in the traditional salt industry, the generation of young people will enhance their willingness to work in the traditional salt industry, retain the precious human resources of the industry and create more employment opportunities for the society. Based on the above research directions, the following expected benefits are summarized.

Table 5. Community survey experience and event promotion.

$\begin{aligned} & \text { The first stage } \\ & \text { (Background) }\end{aligned}$
$\begin{aligned} & \text { Gather } \\ & \text { Thformation } \\ & \text { Third stage } \\ & \text { (Process) } \\ & \text { Indesplain the process of the event } \\ & \text { Tainan Yantian Experience. }\end{aligned}$

\section{Discussion}

With the development of society and the progress of the times, in the social environment of different periods, the unique geographical environment and the local cultural background are inextricably linked, and thus there is variability. Therefore, this study takes the traditional re-construction of Yantian culture's influence and variation on the business and nature of Yantian culture, and the combination of environmental change and contemporary progress. The future outlook and planning are as follows:

1. Short-term: in-depth visits and video recording

The project was visited on the spot to gain an in-depth understanding of whether there are still elderly or the next generation of traditional salt-making people in the Yantian community in Tainan. They should understand the history and characteristics of the past, collect and consolidate, and classify and compare differences. Through the audio-visual presentation of the local culture, interviewing the story with the elders, introducing the local characteristics planning and analysis, and gathering 
them to inform the tourists, let the public know more about the cultural characteristics of Taiwan's salt industry.

2. Mid-term: cultivating talents and promoting skills

Cultivate specialized commentators, introduce regional development characteristics and historical and cultural backgrounds, and introduce talents in Yantian and traditional salt-manufacturing skills, create employment opportunities in Yantian, Tainan, and improve the skills of those returning home, as well as regional development, and promotion.

3. Long-term: establishing an art village and developing sightseeing

Tainan Yantian is sparsely populated year by year, and local characteristics lack long-term operation and improvement. However, the Yantian community in Tainan has abundant local resources. There are many characteristic landmarks in the local area. It is hoped that the redesign project will be carried out through design planning. Develop sightseeing exhibitions, cultural and ecological experiences, let local people participate in the project, and promote the Yantian ecological culture and experience the traditional life of the salt farmers. Not only local sightseeing, but also local specialty products should be designed to make souvenirs for public collection.

Author Contributions: W.-H.C. deals with project administration, writing-review and editing, T.-H.H. deals with investigation, Writing-original draft. All authors have read and agreed to the published version of the manuscript.

Funding: This research received no external funding.

Conflicts of Interest: The authors declare no conflicts of interest.

\section{References}

1. Dewey, J. Democracy and Education: An Introduction to the Philosophy of Education; Macmillan: New York, NY, USA, 1923.

2. Dennison, P. Reflective practice: The enduring influence of Kolb's experiential learning theory. Compass J. Learn. Teach. Univ. Greenwich 2010, 9, 23-28. [CrossRef]

3. Burgoyne, J.G.; Hodgson, V.E. Natural learning and managerial action: A phenomenological study in the field setting. J. Manag. Stud. 1983, 20, 387-399. [CrossRef]

4. Zhang, F.; Fang, J. Taiwan's Salt Industry, 1st ed.; Hiking Culture Enterprise Co, Ltd.: Cigu, Tainan, Taiwan, 2008; pp. 30-95.

5. Forlizzi, J.; Disalvo, C.; Hanington, B. On the relationship between emotion, experience and the design of new products. Des. J. 2003, 6, 29-38. [CrossRef]

6. McTaggart, R. Principles for participatory action research. Adult Educ. Q. 1991, 41, 168-187. [CrossRef]

7. Schon, D.A. The Reflective Practitioner: How Professionals Think in Action; Basic Books: New York, NY, USA, 1983.

8. Schön, D.A. Educating the Reflective Practitioner; Jossey-Bass: San Francisco, CA, USA, 1987; pp. 1-10.

9. Chen, H. Educational Action Research; Shtabook Publishing Co.: Taipei, Taiwan, 1998.

10. Auty, S.; Elliott, R. Fashion involvement, self-monitoring and the meaning of brands. J. Prod. Brand Manag. 1998, 7, 109-123. [CrossRef]

11. Eisner, E.W. Educational reform and the ecology of schooling. Teach. Coll. Rec. 1992, 93, 610-627. 